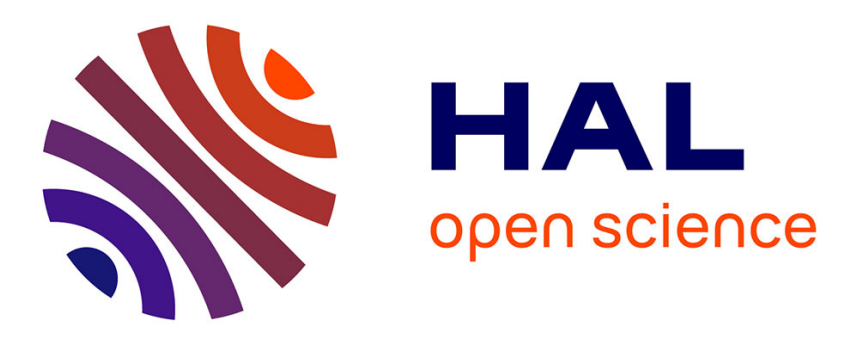

\title{
Out-of-Equilibrium Body Potential Measurement on Silicon-on-Insulator With Deposited Metal Contacts
}

Miltiadis Alepidis, Aude Bouchard, Cécile Delacour, Maryline Bawedin, Irina Ionica

\section{- To cite this version:}

Miltiadis Alepidis, Aude Bouchard, Cécile Delacour, Maryline Bawedin, Irina Ionica. Out-ofEquilibrium Body Potential Measurement on Silicon-on-Insulator With Deposited Metal Contacts. IEEE Transactions on Electron Devices, 2020, 67 (11), pp.4582-4586. 10.1109/TED.2020.3023872 . hal-03090124

\section{HAL Id: hal-03090124 \\ https://hal.science/hal-03090124}

Submitted on 31 Dec 2020

HAL is a multi-disciplinary open access archive for the deposit and dissemination of scientific research documents, whether they are published or not. The documents may come from teaching and research institutions in France or abroad, or from public or private research centers.
L'archive ouverte pluridisciplinaire HAL, est destinée au dépôt et à la diffusion de documents scientifiques de niveau recherche, publiés ou non, émanant des établissements d'enseignement et de recherche français ou étrangers, des laboratoires publics ou privés. 


\title{
Out-of-equilibrium body potential measurement on silicon-on-insulator with deposited metal contacts
}

\author{
Miltiadis Alepidis, Aude Bouchard, Cecile Delacour, Maryline Bawedin, Irina Ionica
}

\begin{abstract}
This article focuses on one of the floating body effects in siliconon-insulator (SOI) substrates, the out-of-equilibrium body potential. Unlike the already existing studies which are exploring either SOI fully-fabricated devices or SOI wafers measured with pressure probes, here the out-ofequilibrium body potential is explored in SOI substrates with deposited metal contacts. Chromium and gold/titanium contacts of various geometries were deposited on silicon films of SOI and the floating body potential was examined in each case. The effect of annealing on the device behavior was also investigated. The performance of the deposited metal contacts is evaluated through current and potential monitoring under quasi-static conditions. Depending on the workfunction difference between metal and silicon film, the current measurements show that the contact behavior is mainly ohmic-like or Schottky-like. While body potential manifests itself with Schottky-like contacts, it does not seem to exhibit a significant response with ohmic contacts. The influence of the contact architecture on the body potential signature is illustrated, enabling the selection of the proper contact layout for an enhanced body potential response.
\end{abstract}

Index Terms - out-of-equilibrium, body potential, silicon on insulator substrates, SOI, metal-silicon contacts

\section{INTRODUCTION}

Although fully depleted silicon on insulator (SOI) field-effect transistors (FET) have improved performance compared to partially depleted devices, they are still not completely immune to floating body effects [1-5]. Even though the floating body effects are usually not desirable for the transistor operation [5], they can be exploited for practical applications [3]. For example, one of the floating body effects is the out-of-equilibrium body potential $\left(\mathrm{V}_{\mathrm{B}}\right)$; it was extensively described for FD-SOI devices and used for DRAM applications [6]. The body potential variation in the device stems from the lack or excess of carriers in the Si film. A lack of carriers occurs while the gate voltage drives the Si film from depletion into inversion/accumulation and carriers are not instantaneously provided by the contacts. Under these conditions, the body potential simply follows the gate voltage and perishes after the injection of the carriers needed for the return to equilibrium. This effect was also measured in SOI wafers with the pseudo-MOSFET method [7], in which metallic pressure-probes are used as source/drain contacts and the silicon bulk serves as a back gate [2]. In this configuration, the body potential proved to be suitable for biochemical detection purposes since it exhibits a shift when charged molecules are placed on the top surface of the silicon film [7]. Consequently, the potential of applications is huge, since $\mathrm{V}_{\mathrm{B}}$ monitoring can extend the current measurements $[8,9]$ that are typically used for the biochemical detection with FETs. However in the present status, $V_{B}$ was measured on SOI with a specific probe station with controlled pressure applied on the probes, which is known to provide ohmic contacts to the Si film [2]. A

Manuscript submitted for review on June 2020. (Corresponding author: M Alepidis, e-mail: miltiadis.alepidis@grenoble-inp.fr).

M. Alepidis, A. Bouchard, M. Bawedin, I. Ionica are with IMEP-LaHC mixed research unit, governed by CNRS, University Grenoble Alpes, Grenoble-INP and University Saint Mont Blanc, located in 3 Parvis Louis Néel, CS 50257, 38016 Grenoble, France.

C. Delacour is with Neel Institut CNRS, University Grenoble Alpes, 25 rue des Martyrs BP 16638042 Grenoble, France pragmatic use for sensing purposes requires fabrication of realistic integrated devices with metal contacts pads on top of the Si films which are not dependant on a particular measurement system. Metal contacts on SOI, inspired by the pseudo-MOSFET, have already been successfully fabricated previously [10-14], with widely used metals and alloys. These studies, focus on current measurements for device characterization and sometimes consider the Schottky barriers between the metal contacts and the low doped Si film. However, they do not discuss the body potential response and the key question is whether the out-of-equilibrium body potential manifests itself in such devices configuration.

The aim of this paper is to give insights on the physical phenomena and the technological choices provoking an out-ofequilibrium body potential response in an SOI with metal deposited contacts, when the backgate is scanned from accumulation to inversion and vice-versa. We explore the use of chromium $(\mathrm{Cr})$ and gold/titanium $(\mathrm{Au} / \mathrm{Ti})$ pads on both drain current and body potential. The effects of thermal annealing and geometry of pads are also investigated.

\section{EXPERIMENTAL Procedure}

The devices under test are fabricated on SOI with 70nm Si film and $145 \mathrm{~nm}$ buried oxide (BOX) thicknesses. The Si film is p-type with a doping concentration of $\mathrm{N}_{\mathrm{a}} \approx 10^{15} \mathrm{~cm}^{-3}$. Silicon mesas of $5 \times 5 \mathrm{~cm}^{2}$ were isolated by lithography and reactive ion etching. The top native oxide layer present on the $\mathrm{Si}$ was removed in a 5\% HF solution for 5 seconds, prior to the metal deposition. The chromium patterns were fabricated by sputtering (300nm Cr layer thickness) on top of the wafer maintained at $120^{\circ} \mathrm{C}$, followed by lithography and etching. The $\mathrm{Au} / \mathrm{Ti}$ contacts were fabricated with a lift-off process after evaporating $5 \mathrm{~nm} \mathrm{Ti}$ and $30 \mathrm{~nm}$ Au layers at room temperature, in vacuum. The metal pads are either circular with a radius of $100 \mu \mathrm{m}$ or square of $100 \mu \mathrm{m}$ side and they are positioned at various distances between them $(\mathrm{d}=0.3 \mathrm{~mm}, 0.5 \mathrm{~mm}$ and $1 \mathrm{~mm})$, as illustrated in the schematic of Fig.1.

a)

$$
\text { Metal contacts }
$$

b)
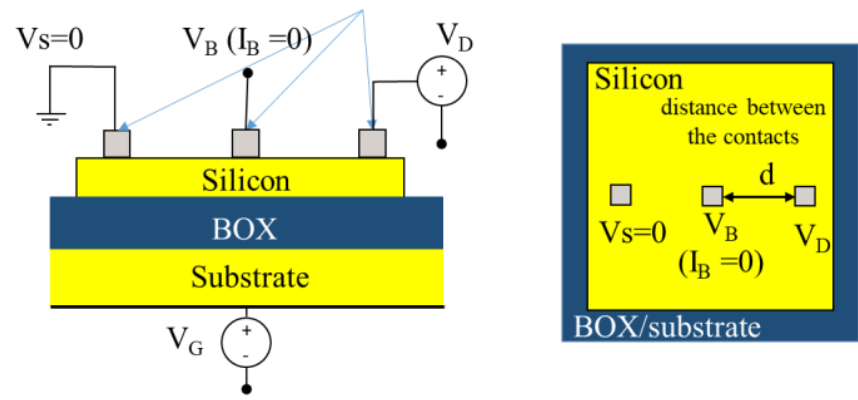

Fig. 1: Device schematics. a) Cross-section view with the three metal contacts that correspond to source, drain and body. b) Top view of the device.

The electrical characterization was realised in a standard semiconductor probe station. An Agilent B1500 semiconductor analyser and four source/measure units were used for each one of the device terminals (Fig.1a). The drain current $I_{D}$, gate current $I_{G}$ and body potential $\mathrm{V}_{\mathrm{B}}$ were measured during sweeping the gate voltage $\mathrm{V}_{\mathrm{G}}$ from accumulation to inversion (forward scan) and vice-versa (reverse scan), with a step of $50 \mathrm{mV}$. The hold time (before the first 
measurement) and delay time (before each measurement point) were set to 30 s and $100 \mathrm{~ms}$ respectively, insuring an equilibrium starting point and reduced fluctuations in the monitored currents. The source was grounded, the drain voltage $\mathrm{V}_{\mathrm{D}}$ was set to $0.1 \mathrm{~V}$ and zero current condition was imposed to body contact for all the measurements. For $I_{D}$ versus $V_{D}$, the voltage step was set to $20 \mathrm{mV}$. The $V_{G}$ values selected correspond to subthreshold, low inversion and strong inversion regimes for the device under test.

\section{RESULTS AND DISCUSSIONS}

\section{A. Effect of the metal on the device response}

Fig.2 illustrates the $I_{D}-V_{G}$ characteristics curves for $\mathrm{Cr}$ and $\mathrm{Au} / \mathrm{Ti}$ circular contacts placed in the centre of the device at a distance $\mathrm{d}=1 \mathrm{~mm}$ and a typical pseudo-MOSFET curve obtained with pressure probes of the same wafer. In strong inversion $\left(\mathrm{V}_{\mathrm{G}}>0\right)$, both metals have an $I_{D}$ in the same order of magnitude as the pseudo-MOSFET measurement, with higher ON-current and a steeper subthreshold slope for $\mathrm{Au} / \mathrm{Ti}$ contacts. In depletion regime, for the $\mathrm{Cr}$ contacts $\mathrm{I}_{\mathrm{D}}$ drops in the order of $100 \mathrm{pA}$ (similarly to the pseudo-MOSFET curve), while for $\mathrm{Au} / \mathrm{Ti}$ it has a minimum value $\sim 1 \mathrm{nA}$. In accumulation $\left(\mathrm{V}_{\mathrm{G}}<0\right), \mathrm{I}_{\mathrm{D}}$ increases back with $\mathrm{Cr}$ contacts while it stays constant around $20 \mathrm{nA}$ for $\mathrm{Au} / \mathrm{Ti}$, contrary to pseudo-MOSFET which has a hole current in the $\mu \mathrm{A}$ range. It is evident that for the fabricated devices, the $\mathrm{Cr}$ contacts produce an $\mathrm{I}_{\mathrm{D}}-\mathrm{V}_{\mathrm{G}}$ shape similar to the pressure controlled probes on Si films with lower current values. Note however that a better electrical contact for electrons is obtained with $\mathrm{Au} / \mathrm{Ti}$ pads.

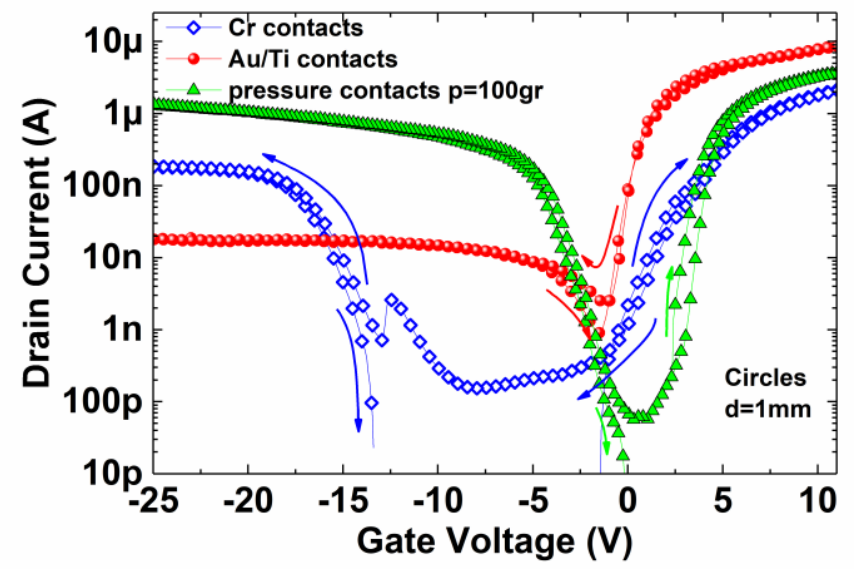

Fig. 2: $I_{D}-V_{G}$ characteristic curves on semi-log scale $\mathrm{Cr}, \mathrm{Au} / \mathrm{Ti}$ and controlled pressure probes on top of $70 \mathrm{~nm}$ thick $\mathrm{Si}$ on $145 \mathrm{~nm}$ thick BOX. These curves are representative of all the devices tested.

Fig. 3 presents the $I_{D}-V_{D}$ curves of the same devices as in Fig. 2 for various $\mathrm{V}_{\mathrm{G}}$ voltages. The $\mathrm{V}_{\mathrm{G}}$ values were selected in order the $\mathrm{Si}$ film to be in the subthreshold or inversion/accumulation regimes for each device. In all cases, $I_{D}$ has a linear behaviour for low $V_{D}$ values. $\mathrm{Au} / \mathrm{Ti}$ contacts have a clear ohmic response for $\mathrm{V}_{\mathrm{G}}>0$ and they show better conductivity compared to $\mathrm{Cr}$. For $\mathrm{V}_{\mathrm{G}}<0$ with $\mathrm{Cr}$ contacts, $\mathrm{I}_{\mathrm{D}}$ quickly deviates from the linear behaviour when $V_{D}$ increases while $\mathrm{Au} / \mathrm{Ti}$ contacts show very small current values with a lesser dependence on $\mathrm{V}_{\mathrm{G}}$. This is consistent with Fig.2, since for accumulation we observe a low value plateau current for $\mathrm{Au} / \mathrm{Ti}$ contacts.

Theoretically, the type of the contact is defined by the workfunction difference between the metal and the semiconductor [15]. For the p-type silicon used, the workfunction is calculated at $4.91 \mathrm{eV}$. Consequently, we expect a rectifying behaviour for the $\mathrm{Cr}$ $\left(\phi_{\mathrm{Cr}}=4.5 \mathrm{eV}[16]\right)$ contacts and a non-rectifying for $\mathrm{Au} / \mathrm{Ti}\left(\phi_{\mathrm{Au}} \geq 5.1 \mathrm{eV}\right.$ [16]). Note that the Ti layer is deposited for adhesion between $\mathrm{Si}$ and $\mathrm{Au}$ and for $5 \mathrm{~nm}$ layer thickness, Ti should diffuse into the grain boundaries of $\mathrm{Au}$ [17], as a result it should not affect the electrical response [18]. However, the experimental $I_{D}-V_{D}$ curves are not entirely ohmic or Schottky on the full range of the $\mathrm{V}_{\mathrm{G}}$, probably because the actual carrier concentration in the Si film (including under the contacts) is modified by $\mathrm{V}_{\mathrm{G}}$. The aim here is not to provide a full understanding of this rather complex problem. It is important to underline that for low $\mathrm{V}_{\mathrm{D}}$, most of the curves show a fairly linear behaviour. We can therefore conclude that carriers should be provided in all the cases and we can proceed to the $V_{B}$ measurements.
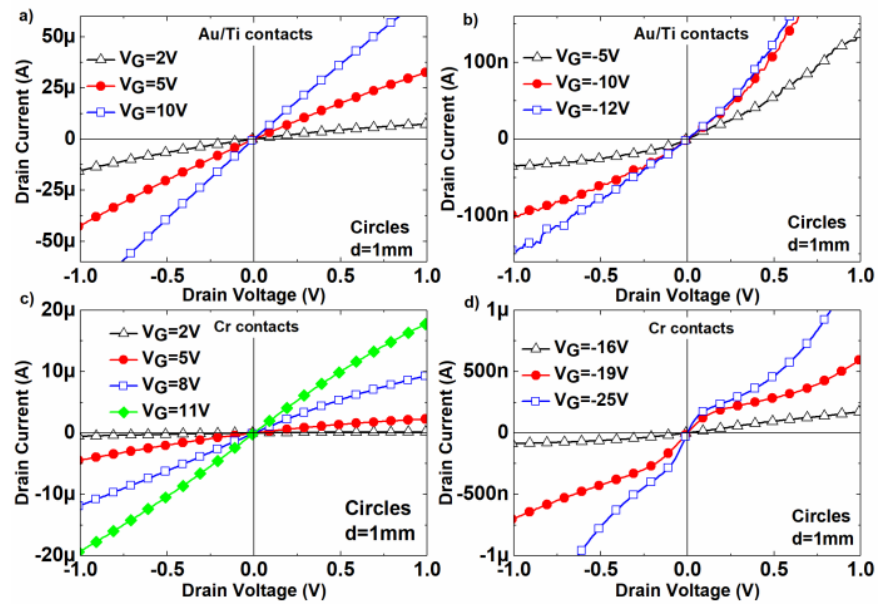

Fig. 3: $I_{D}-V_{D}$ curves for Au/Ti contacts with a) $V_{G}>0$ (Si film in inversion) and b) $\mathrm{V}_{\mathrm{G}}<0$ (Si film in accumulation) and for $\mathrm{Cr}$ contacts with c) $\mathrm{V}_{\mathrm{G}}>0$ and d) $\mathrm{V}_{\mathrm{G}}<0$. Same devices as in Fig. 2

Fig.4 depicts the $V_{B}$ response of the devices under test. $V_{B}$ with the $\mathrm{Cr}$ contacts is constant in accumulation and inversion regimes with the value of $50 \mathrm{mV}$ (corresponding to $\mathrm{V}_{\mathrm{D}} / 2$ ). In the depletion regime it follows $V_{G}$ and drops quickly to the equilibrium value. The rise of $V_{B}$ is associated to the out-of-equilibrium lack of electrons at the beginning of the depletion/low inversion regime. The drop appears when the carriers are efficiently injected and the device returns to equilibrium; this is also evident through the $\mathrm{I}_{\mathrm{G}}$ peak illustrated in the inset of the Fig.4. The Au/Ti contacts present small variations of $\mathrm{V}_{B}$ for negative $V_{G}$ and reaches $50 \mathrm{mV}$ for positive $V_{G}$. The typical response of out-of-equilibrium $V_{B}$ for the pseudo-MOSFET is similar to the one observed with $\mathrm{Cr}$, but lower in value. The shift and the range of the $V_{B}$ response between $\mathrm{Cr}$ and pressure probes is agreement with Fig.2 since it is associated with the depletion regime of each device. Additionally, SOI MOSFETs give a comparable $V_{B}$ signature as reported in the literature $[6,7,19]$. Besides a stronger $V_{B}$ signature, the $\mathrm{Cr}$ contacts provided less $\mathrm{I}_{\mathrm{D}}$ current than $\mathrm{Au} / \mathrm{Ti}$ leading to the conclusion that a higher resistivity contact might be more appropriate for a strong $\mathrm{V}_{\mathrm{B}}$ response. In order to check this hypothesis, we proceed to annealing of the devices, which is expected to improve the contacts.

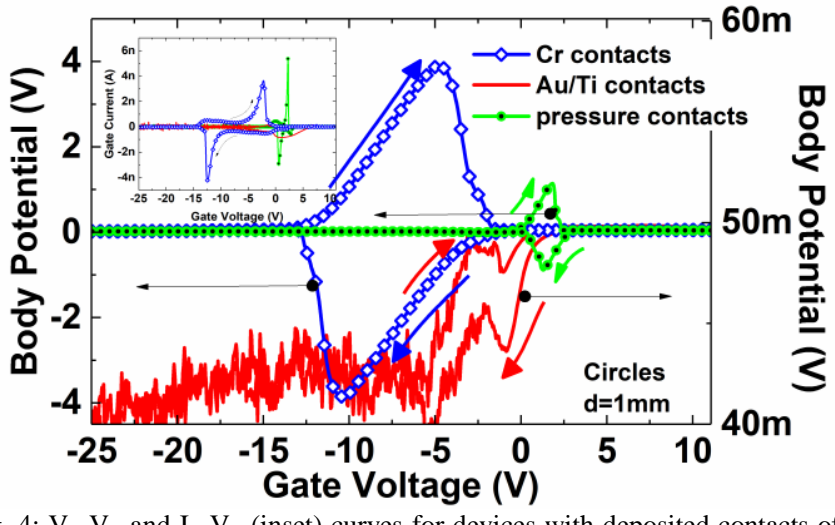

Fig. 4: $V_{B}-V_{G}$ and $I_{G}-V_{G}$ (inset) curves for devices with deposited contacts of $\mathrm{Cr}, \mathrm{Au} / \mathrm{Ti}$ and with controlled pressure probes. The right $\mathrm{y}$-axis corresponds to the body potential of $\mathrm{Au} / \mathrm{Ti}$ contacts, given in a smaller scale than $\mathrm{Cr}$ and pseudo-MOSFET (left y-axis). 


\section{B. Effect of annealing}

The wafers were annealed for one hour in an oven at $300^{\circ} \mathrm{C}$ under high vacuum. The wafers with $\mathrm{Au} / \mathrm{Ti}$ metal pads showed slightly increased contact conductivity after annealing (higher $\mathrm{I}_{\mathrm{D}}$ ) but no increase in $V_{B}$ response and therefore we exclude them from the following studies. For a device with $\mathrm{Cr}$ contacts, a typical $\mathrm{I}_{\mathrm{D}^{-}}-\mathrm{V}_{\mathrm{G}}$ curve before and after annealing is presented in Fig.5. We notice higher ON-currents for accumulation and strong inversion, and an increase of the current values in the depletion region. Additionally, the off-region of the device is narrowed after annealing, similar to results previously obtained in the literature for SOI with pressure probes [20]. The resistivity of the contacts after annealing is reduced, especially for holes, and the $I_{D}-V_{D}$ curves (presented as an inset of Fig.5) have a linear response for both types of carriers after annealing (unlike in Fig.3d). The annealing process clearly improves the contact conductivity for the chromium contacts, but what is its effect on the $\mathrm{V}_{\mathrm{B}}$ response?

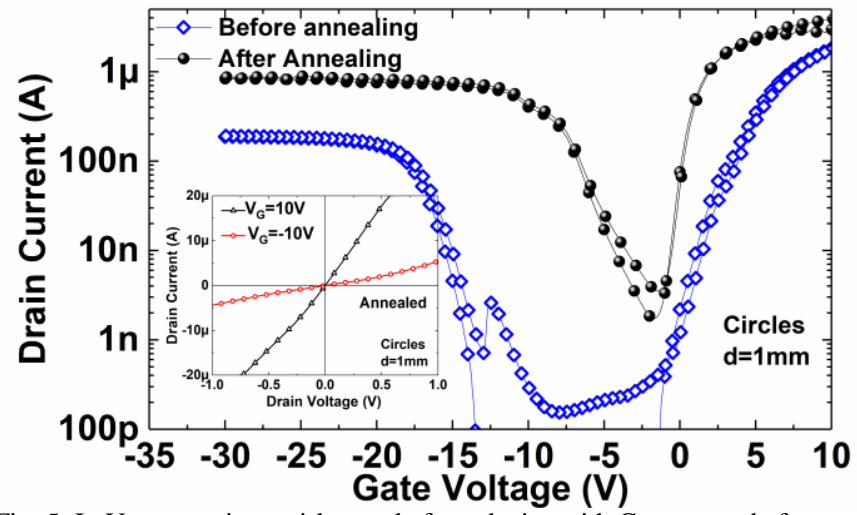

Fig. 5: $\mathrm{I}_{\mathrm{D}}-\mathrm{V}_{\mathrm{G}}$ curves in semi-log scale for a device with $\mathrm{Cr}$ contacts before and after annealing.

Fig.6 illustrates $\mathrm{V}_{\mathrm{B}}-\mathrm{V}_{\mathrm{G}}$ and $\mathrm{I}_{\mathrm{G}}-\mathrm{V}_{\mathrm{G}}$ (inset) curves for the same device before and after annealing. The $\mathrm{V}_{\mathrm{B}}$ response is obviously diminished for both scanning directions. The deformation of the gate current (inset of Fig.6) shape signifies that the electrical quality of the contact affects the minority carrier injection in the silicon film. Before annealing, the minority carriers cannot be provided instantaneously. After annealing, we notice a significant decrease in the displacement current which implies that the respective amount of carriers is injected almost instantly in the silicon film, therefore, the device does not enter an out-of-equilibrium regime and $\mathrm{V}_{\mathrm{B}}$ remains constant.

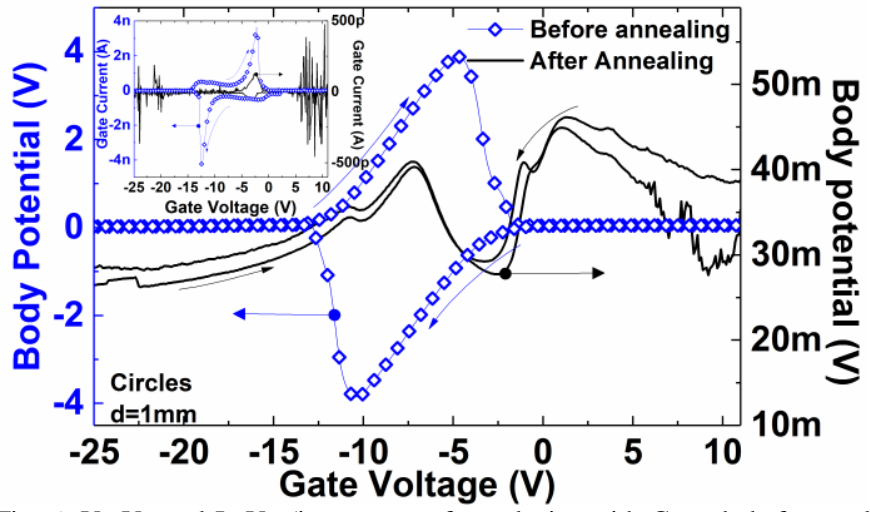

Fig. 6: $\mathrm{V}_{\mathrm{B}}-\mathrm{V}_{\mathrm{G}}$ and $\mathrm{I}_{\mathrm{G}}-\mathrm{V}_{\mathrm{G}}$ (inset curves for a device with $\mathrm{Cr}$ pads before and after annealing. The right y-axis corresponds to the body potential after annealing in a smaller scale.

The effects of the materials and the process in the above analysis reveal that an excellent contact quality, with low resistance, does not guarantee a favorable $\mathrm{V}_{\mathrm{B}}$ response. Indeed, a small contact resistance allows rapid carrier injection, leading to the suppression of the outof-equilibrium phenomenon. On the contrary, out-of-equilibrium $V_{B}$ necessitates existence of barriers preventing the contacts to provide the carriers instantly. Annealing of the $\mathrm{Cr}$ contacts transforms towards a purely ohmic behaviour, eliminating the Schottky barrier and hence the $V_{B}$ variations vanish.

For the next study of the effect of the distance between the contacts and the shape of the pads for $V_{B}$ engineering, we'll focus on devices with chromium contacts, without annealing.

\section{Distance between metal contacts}

The channel length and width of FD-MOSFETs affect significantly their drive current. Considering the unconventional 3D geometry in pseudo-MOSFET and the necessary modifications in the models to accurately describe its current [2], we investigate the effect on $\mathrm{V}_{\mathrm{B}}$. While we can hardly correlate a parameter to the width, the channel length can be easily associated to the distance between the metal contacts. Initially, we monitored $V_{B}$ in a three terminal configuration as in Fig.1a. We measured three devices with distances between the contacts of $0.3 \mathrm{~mm}, 0.5 \mathrm{~mm}$ and $1 \mathrm{~mm}$. The curves are illustrated in Fig.7. The body potential variation is pronounced in all devices but the values are lower for $\mathrm{d}=0.3 \mathrm{~mm}$. For $\mathrm{d}=0.5 \mathrm{~mm}$ and $\mathrm{d}=1 \mathrm{~mm}$ the difference between the curves seems minor since the signature is identical in shape and only slightly shifted.

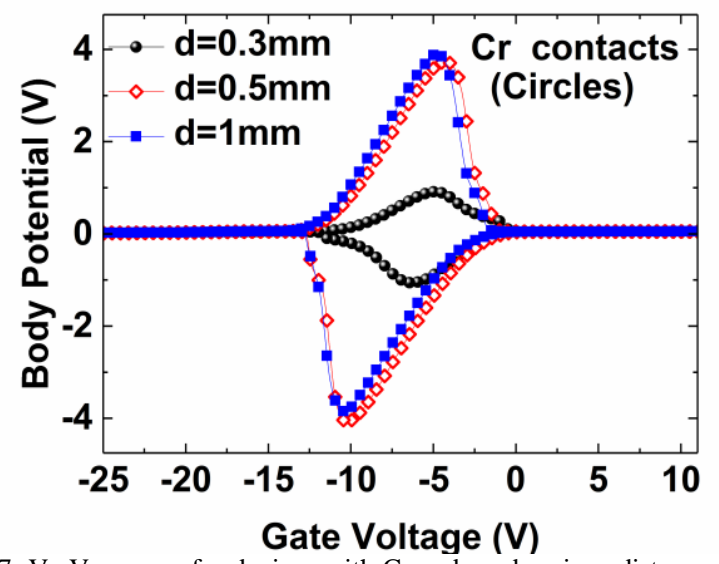

Fig. 7: $\mathrm{V}_{\mathrm{B}}-\mathrm{V}_{\mathrm{G}}$ curves for devices with $\mathrm{Cr}$ pads and various distances between the contacts.

To eliminate any variability issues between the devices, $V_{B}$ was also monitored between various contacts on the same device having four circular metal pads and a distance of $1 \mathrm{~mm}$ between them (Fig 8). The first contact (P1), which acts like the source, is grounded and $V_{B}$ was monitored on one of the other three contacts (P2, P3, P4). Under these experimental conditions, the drain contact is floating, hence no $\mathrm{V}_{\mathrm{D}}$ is applied. Fig.8 illustrates the response of the body potential and the respective $\mathrm{I}_{\mathrm{G}}$ (inset).

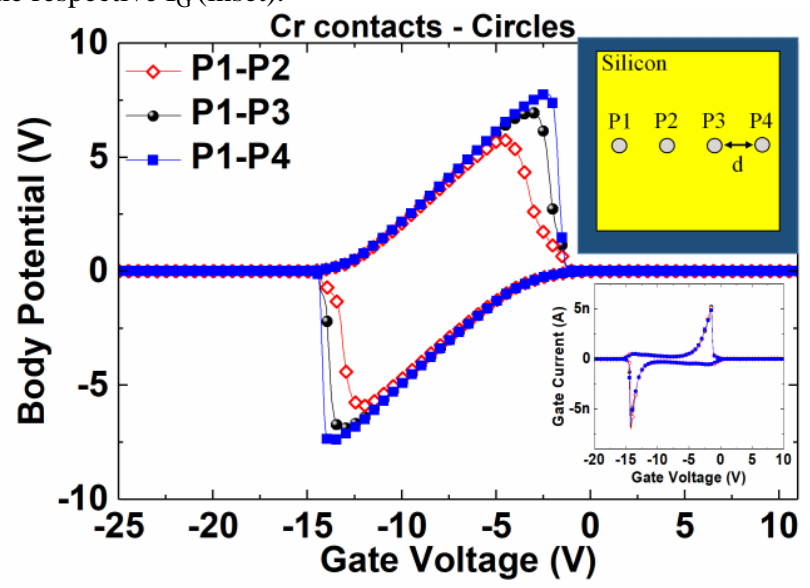

Fig. 8: $V_{B}-V_{G}$ curves for various contacts configurations. $I_{G}-V_{G}$ curves (bottom inset) and schematic top view of the device (top inset). 
Body potential response is affected by the distance from the source, unlike the gate current which is perfectly superposed for all the experiments. Although, the value of the body potential stays constant for each position during the linear increase, $V_{B}$ returns to the equilibrium value in a sharper way if the distance between the contacts increases. $\mathrm{I}_{G}$ peak value always occurs when $\mathrm{V}_{\mathrm{B}}$ returns to the equilibrium value, clarifying that the BOX capacitance charge concerns the full area of the Si mesas and is the same for a given mesa regardless of the distance. Larger distance between the contacts results also in higher $V_{B}$ values. When the $\mathrm{Si}$ film is depleted, channel time constant value is large [21]. Consequently, the extra time needed for the carriers to be transferred at distant contacts, drives $\mathrm{V}_{\mathrm{B}}$ to higher values.

Contact layout can have an important role on the tuning of the device and more specifically on $\mathrm{V}_{\mathrm{B}}$. Another factor that affects the electric field distribution in the silicon mesa is the contact shape which we examine next.

\section{Shape of the contact}

Square and circular metal contacts are compared in terms of body potential response in Fig. 9. In the graph, the comparison is realized for three distances (d) between the contacts. For $\mathrm{d}=1 \mathrm{~mm}$, the response is almost not affected by the contact shape. However, the impact of the shape becomes strong on the $\mathrm{V}_{\mathrm{B}}-\mathrm{V}_{\mathrm{G}}$ curves when the distance between the contacts is in the same order of magnitude as their own size. This effect is probably related to the current density distribution in the thin Si film, which is associated to the electric field distribution. Simulations in pseudo-MOSFET with point contacts have shown a strong current density around the contacts in the Si film [22]. In the case of $100 \mu \mathrm{m}$ size pads, spaced by $300 \mu \mathrm{m}$, the electric field lines are affected by their shape and they might interact. The $\mathrm{V}_{\mathrm{B}}$ response, which is related to the way that the carriers are injected in the film, will be more sensitive to the shape of the contacts if they are closed to one another. For practical applications, it is more convenient to use contacts with a stronger separation in order to reduce this effect and have a $\mathrm{V}_{\mathrm{B}}$ less dependent on the contact in-plane geometry.

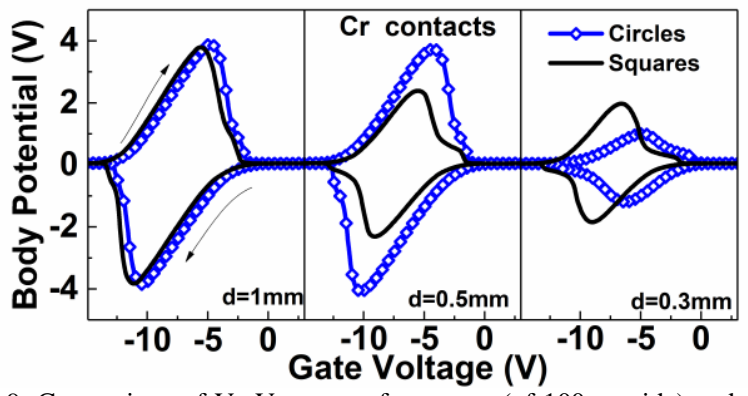

Fig. 9: Comparison of $\mathrm{V}_{\mathrm{B}}-\mathrm{V}_{\mathrm{G}}$ curves for square (of $100 \mu \mathrm{m}$ side) and circular (of $100 \mu \mathrm{m}$ diameter) metal pads, with various distances between the contacts

\section{CONCLUSIONS}

This work focuses on the out-of-equilibrium body potential obtained on SOI wafers with metal-deposited contacts and gives an insight on the respective physics. The structures were inspired by the biochemical detection capability of the body potential in SOI wafers measured with pressure-controlled probes (pseudo-MOSFET configuration). The devices developed here are more adapted for applications since they replace the probes of a particular probestation with metal contacts directly deposited on the Si film. We selected $\mathrm{Cr}$ and $\mathrm{Au} / \mathrm{Ti}$ for the contacts since they are theoretically expected to form Schottky or ohmic for the Si doping used. While $\mathrm{Cr}$ contacts show higher contact resistance and hence lower ON-current, they clearly give strong and pronounced $\mathrm{V}_{\mathrm{B}}$ response, similar to the pseudo-MOSFET configuration. On the contrary, Au/Ti devices have higher current, but almost no body potential response. Annealing of the samples reduces the contact resistivity, but also reduces significantly the $\mathrm{V}_{\mathrm{B}}$ signal. This illustrates the importance of having some barriers between the contacts and the Si film that prevent the carriers to be instantly provided during the $\mathrm{V}_{\mathrm{G}}$ scan. The architecture of the devices was also considered in the $V_{B}$ response through the investigation of the distance between the metal contacts and the contact shape. The results show that when the contacts are placed too close to each other, $V_{B}$ weakens. The distance between the contacts affects also the path that the body potential follows to return to the equilibrium value. The comparison with $\mathrm{I}_{\mathrm{G}}$ suggests that it stems from the diffusion of the carriers in the silicon film. Finally, the shape of the metal contact seems to be important when it is comparable in size with the distance between the contacts.

The overall outcome of this work indicates that for applications based on $V_{B}$ response (e.g charge sensing), the use of Schottky contacts would be preferable to the use of ohmic contacts.

\section{ACKNOWLEDGMENTS}

The authors thank SOITEC for providing the wafers in this study and especially Dr. Frédéric Allibert for the inspiring conversations.

\section{REFERENCES}

[1] S. Cristoloveanu, M. Bawedin, I. Ionica, Solid-State Electronics 117 (2016) 10-36.

[2] S. Cristoloveanu, D. Munteanu, M.S.T. Liu, IEEE Transactions on Electron Devices 47 (2000) 1018-1027.

[3] M. Bawedin, S. Cristoloveanu, J.G. Yun, D. Flandre, Solid-State Electronics 49 (2005) 1547-1555.

[4] J.G. Fossum, S. Krishnan, O. Faynot, S. Cristoloveanu, C. Raynaud, IEEE Electron Device Letters 16 (1995) 542-544.

[5] Ying-Che Tseng, W.M. Huang, D.C. Diaz, J.M. Ford, J.C.S. Woo, IEEE Electron Device Letters 19 (1998) 351-353.

[6] M. Bawedin, S. Cristoloveanu, D. Flandre, F. Udrea, Solid-State Electronics 54 (2010) 104-114.

[7] L. Benea, M. Bawedin, C. Delacour, I. Ionica, Solid-State Electronics 143 (2018) 69-76.

[8] Y.-C. Syu, W.-E. Hsu, C.-T. Lin, ECS J. Solid State Sci. Technol. 7 (2018) Q3196-Q3207.

[9] S.A. Pullano, C.D. Critello, I. Mahbub, N.T. Tasneem, S. Shamsir, S.K. Islam, M. Greco, A.S. Fiorillo, Sensors 18 (2018) 4042.

[10] S. Cristoloveanu, T.V.C. Rao, Q.T. Nguyen, J. Antoszewski, H. Hovel, P. Gentil, L. Faraone, IEEE Transactions on Electron Devices 56 (2009) 474-482.

[11] V.A. Kushner, J. Yang, J. Choi, T. Thornton, D. Schroder, ECS Trans. 2 (2006) 491-502.

[12] K. Park, P. Nayak, S. Cristoloveanu, D.K. Schroder, IEEE Transactions on Electron Devices 56 (2009) 1269-1276.

[13] L. Hollt, M. Born, M. Schlosser, I. Eisele, J. Grabmeier, A. Huber, IEEE Transactions on Electron Devices 54 (2007) 2685-2689.

[14] M. Arsalan, X. Cao, B. Lu, Y. Chen, A. Zaslavsky, S. Cristoloveanu, M. Bawedin, J. Wan, in: 2018 IEEE SOI-3D-Subthreshold Microelectronics Technology Unified Conference (S3S), 2018, pp.13.

[15] Semiconductor Material and Device Characterization, John Wiley \& Sons, Inc., Hoboken, NJ, USA, 2005.

[16] H.B. Michaelson, Journal of Applied Physics 48 (1977) 4729-4733.

[17] T.C. Tisone, J. Drobek, Journal of Vacuum Science and Technology 9 (1972) 271-275.

[18] I. Polishchuk, P. Ranade, Tsu-Jae King, Chenming Hu, IEEE Electron Device Letters 22 (2001) 444-446.

[19] H. Park, J.-P. Colinge, S. Cristoloveanu, M. Bawedin, Physica Status Solidi (a) n/a (n.d.) 1900948.

[20] G. Hamaide, F. Allibert, H. Hovel, S. Cristoloveanu, Journal of Applied Physics 101 (2007) 114513.

[21] K. Romanjek, F. Lime, G. Ghibaudo, C. Leroux, Solid-State Electronics 47 (2003) 1657-1661.

[22] D. Munteanu, S. Cristoloveanu, E. Guichard, Solid-State Electronics 43 (1999) 547-554. 